\title{
¡Muerte a lo real! Notas sobre diez años de práctica documental expandida
}

\author{
Pablo Martínez Zárate \\ Universidad Iberoamericana, México \\ pablomartinezzarate@gmail.com \\ https://orcid.org/0000-0001-7219-0665
}

\section{Death to the real! Notes on ten years of expanded documentary practice}

\begin{abstract}
RESUMEN
Este artículo recupera la experiencia de creación de narrativas documentales transmedia a lo largo de una década. En este caso, se pone énfasis en la práctica documental como un dispositivo crítico desde donde articular estrategias de apropiación tecnológica con fines de investigación artística, reconociendo la herencia del cine crítico latinoamericano en una serie de prácticas autorales y desde el Laboratorio

Iberoamericano de Documental de la Universidad lberoamericana Ciudad de México, así como coproducciones, comisiones y colaboraciones. El texto se estructura en tres partes: la primera aborda algunas provocaciones inspiradas en la historia del cine latinoamericano, la segunda presenta un recorrido no-lineal por la producción del autor y algunas

ideas que sostienen su práctica, y finalmente, se ofrecen nociones y modelos de corte metodológico para el desarrollo de proyectos documentales transmedia. Este artículo es una suerte de collage de ideas que entreteje premisas de realización con múltiples experiencias de realización en un espíritu por contribuir, aunque sea mínimamente, a una cartografía de los modos en que la práctica documental se encarna en un contexto cultural y económico como el de Latinoamérica.
\end{abstract}

PALABRAS CLAVE

Diseño transmedia; Creación audiovisual; Arte crítico; Investigación artística; Montaje expandido.

\section{ABSTRACT}

This article recovers the experience of creating documentary transmedia narratives throughout a decade. In this case, it underlines documentary practice as a critical dispositive from which to articulate strategies for technological appropriation with artistic research purposes, recognizing the heritage of critical Latin American cinema in a series of author practices and from the Laboratorio Iberoamericano de Documental at Universidad Iberoamericana Mexico City, as well as coproductions, commissions and collaborations. The text structures in three parts: the first displays some provocations inspired in the history of Latin American cinema, the second presents a non-linear journey on the authors production and some ideas that shape his practice, and finally, it offers notions and methodological models for the development of transmedia documentary projects. This article is a sort of collage of ideas that weaves creative principles with multiple production experiences with the intention of contributing, even discretely, to a cartography of the ways in which documentary practice is incarnated in a cultural and economic context such as that of Latin America.

\section{KEYWORDS}

Transmedia design; Audiovisual creation; Critical art; Artistic research; Expanded montage. 


\section{Sitio de enunciación: Latinoamérica como territorio de crisis}

Latinoamérica es turbulenta, su experiencia sacude. Un estado de crisis latente atraviesa sus fronteras, marca los cuerpos, los nombres, las armas. Las armas que pueden ser, no blancas ni de fuego, sino poéticas. Una ¡muerte a lo real! apela precisamente a estas máquinas poéticas, capaces de reinventar las relaciones que sostienen nuestra realidad herida, es una convocatoria a reimaginar los horizontes de posibilidad. En un territorio marcado por la crisis, el arte, y más todavía un arte de carácter documental -aquel que depende la investigación de la realidad para su confección-, parece atravesado por una sensación de urgencia, de emergencia.

Escribió el insigne documentalista cubano, Santiago Álvarez: "En una realidad convulsa como la nuestra, como la que vive el Tercer Mundo, el artista debe autoviolentarse, ser llevado conscientemente a una tensión creadora en su profesión" (Álvarez, 1988, p. 35). Durante más de diez años, figuras como las de Santiago Álvarez han sido faro para mis procesos de investigación artística dirigidos al trabajo de documental expandido desde Latinoamérica, en concreto desde México?. Más allá de su filiación castrista, su sentido de práctica situada ha sido una condición para reflexionar sobre mi propia expresión en/desde/a través de esta región desmembrada. Este es el objetivo de este texto y el espíritu detrás de su título²: poner en cuestión el horizonte de realidad que, cada vez más, parece insostenible. ¿Qué supone dar muerte a lo real, cómo puede ser semejante provocación compatible con una práctica documental?

Términos como "autoviolencia" o "tensión creadora" contenidos en la cita de Álvarez me hacen pensar en un espíritu reflexivo que regresa constantemente no solamente sobre el contexto de práctica, sino sobre la práctica misma. Lo anterior cobra especial relevancia al hablar de creaciones que se acercan al uso de tecnologías digitales y de vanguardia, sobre todo si consideramos que la gran mayoría de la infraestructura tecnológica es desarrollada fuera de la región. En este sentido, todos los proyectos que he desarrollado a lo largo de los años han recurrido a la implementación de soluciones tecnológicas propias, sin el uso de software o templates preconcebidos en la búsqueda de estrategias artísticas. El mismo Álvarez nos invita a pensar en una apropiación crítica de las tendencias configuradas en "países desarrollados". Sin ignorar los avances tecnológicos, científicos y estéticos en países con condiciones de infraestructura tecnológica distintas, habitualmente consideradas "más avanzadas", Álvarez propone un reconocimiento de estos avances siempre de la mano de una inquisición crítica, de tal manera que nos preguntemos qué direcciones de esas tendencias extranjeras resuenan con los contextos históricos y políticos de nuestras realidades. Al mismo tiempo, cabe recordar que toda tecnología responde a un programa político y en su uso, podemos articular una potencia de réplica o cuestionamiento de dichos programas. Podría denominar esta dinámica como una dialéctica crítica de la tecnología, desde la cual diseñar esquemas de apropiación e innovación tecnológica desde el sur.

La postura crítica parece una condición de posibilidad de toda expresión en un territorio fractura y un desafío a una herencia colonial que, todavía hasta nuestros días, informa nuestras pasiones y fantasmas. Podríamos relacionar estas ideas con las palabras de Glauber Rocha en su Estética del Hambre:

América Latina permanece colonia, y lo que diferencia al colonialismo de ayer del actual es solamente la forma más perfecta del colonizador; y además de los colonizadores, las formas sutiles de aquellos que también, sobre nosotros, arman futuros golpes. El problema internacional de América Latina es todavía un caso de cambio de colonizadores, siendo que una liberación posible estará todavía por mucho tiempo en función de una nueva dependencia. Este condicionamiento económico y político nos llevó al raquitismo filosófico y a la impotencia, que, a veces inconsciente, a veces no, producen en el primer caso la esterilidad y en el segundo la histeria. (Rocha, 1965, p. 52)

A más de medio siglo de que las palabras de Rocha fueron publicadas, ¿cómo han evolucionado los modos de colonización, en qué medida podemos desafiarlos desde una apropiación crítica de la tecnología?

En palabras de Santiago Álvarez, "hay que tomar en cuenta la realidad en que se trabaja. La responsabilidad del intelectual del Tercer Mundo es diferente a la del intelectual del mundo desarrollado" (Álvarez, 1988, p. 35). ¿Cuáles son las responsabilidades del intelectual, en concreto del artista documental, en un territorio como la Latinoamérica del siglo XXI, un territorio marcado por la sangre, la opresión, la injusticia, al mismo tiempo que la riqueza cultural e identitaria que es fuego de expresiones ricas en diversidad a lo largo, ancho y profundo del continente? Todo conocimiento es un conocimiento situado, nos recuerda Dona Haraway (1991), y el arte documental como un camino para la exploración de la realidad y producción del conocimiento parece exigir un reconocimiento del contexto de producción, los recursos con los que contamos, los horizontes de circulación de nuestras piezas, para tejer así narrativas que sean a su vez manifestaciones o vibraciones del ethos y el pathos latinoamericano.

Lo anterior no supone articular expresiones de denuncia directa contra un régimen opresor. Muchas veces, el primer sitio de intervención es el un cuestionamiento de nuestra propia mirada. ¿En qué medida encarnamos tendencias neocolonialistas, es posible librarnos de ellas, qué estrategias tenemos para trabajar hacia la liberación de nuestra expresión? ¿Cómo vemos esta realidad que nos tocó vivir, cómo la transitamos, cómo filtramos nuestras experiencias en 
registros de vida, registros de realidad, que puedan después convertirse en materia prima de una arquitectura concreta de la expresión, ya sea en una película, un webdocumental, una videoinstalación o un proyecto transmedia? En este mirarnos mirar podemos encontrar algunas pistas del espíritu crítico que retomo de autores como Álvarez y Rocha, entre tantos otros, para intentar desplegar nuevas posibilidades de este privilegio nuestro de crear. Porque si ya lo es en cualquier latitud, en territorios marcados por la disparidad social y económica, la práctica artística como camino de realización personal y profesional es incuestionablemente un privilegio.

Este ensayo no pretende responder estas preguntas, por supuesto, sino describir algunas rutas por las que durante más de una década he transitado por esta urgencia de ser latinoamericano, mediante lo que denomino arte o práctica documental. Por ello entiendo una búsqueda por articular un campo metodológico desde el cual concebir, diseñar e implementar proyectos de creación en múltiples plataformas (ver Martínez Zárate, 2021), y no tanto una esfera genérica que la ponga en un sitio específico del mercado audiovisual o los circuitos culturales.

\section{La mirada dislocada: hacia una cartografía mínima de mi práctica documental}

Proponer repasar una trayectoria de producción supone retos de orden (más precisamente, de orden del discurso). Y todo orden de discurso conlleva implicaciones éticas. La práctica documental que he desarrollado en esta década invariablemente se ve atravesada por la pregunta ética, una pregunta que disloca la mirada. ¿Cómo miro, desde dónde miro, para qué miro, qué miro cuando miro, qué queda fuera de cuadro? En este caso, no intentaré hacer una cronología de los proyectos desarrollados en la última década. Por el contrario, rescato algunas líneas de trabajo que han marcado el desarrollo de piezas documentales y esbozo algunos de sus modos de producción, sin agotarles, en un esfuerzo por reflexionar críticamente sobre los modos de sortear los obstáculos de crear narrativas transmedia en Latinaomérica.

Un componente central de mi trabajo artístico ha sido la labor docente. Puedo afirmar que toda mi producción ha estado en estrecha correspondencia con los espacios de docencia que he ocupado a lo largo de la última década. Estos han sido espacios formales e informales, de grado y posgrado, así como talleres de artes en distintos niveles y contextos comunitarios. Esta relación ha evolucionado hasta la fundación, en 2016, del Laboratorio Iberoamericano de Documental dentro del Departamento de Comunicación de la Universidad Iberoamericana, Ciudad de México.

IberoDocslab surgió como una estrategia que condensaba distintas búsquedas. En primer lugar, un interés muy arraigado por recuperar la tradición latinoamericana citada brevemente en el apartado inicial, una tradición que además de habernos heredado obras imprescindibles para acercarse al cine latinoamericano, nos regaló un crisol de pensamiento asociado a la producción. Esto quedó registrado en escritos más extensos como los de Fernando Solanas y Octavio Getino en Argentina, o los de Tomás Gutiérrez Alea en Cuba, o notas sobre producciones y modos de producción como las mismas de Álvarez y Rocha ya citadas, o las palabras de Rubén Gámez en México, de Carlos Mayolo y Luis Ospina en Colombia. De hecho, la génesis del Nuevo cine latinoamericano, podemos localizarla en el puente que Fernando Birri trazó entre la práctica fílmica y el espacio de docencia en la fundación de la Escuela Documental de Santa Fe en 1956. En este sentido, el vínculo entre praxis y docencia es también heredero de esta corriente fundacional latinoamericana. Con la creación del laboratorio, me interesaba recuperar esta búsqueda intelectual e ideológica (de producción de ideas) asociada a la práctica artística; una práctica reflexiva que regrese sobre sí misma y encuentre en la escritura, así sea fragmentaria, una extensión del proceso creativo.

En segunda instancia, una premisa del surgimiento de lberoDocslab, como parte de una de las escuelas de comunicación más antiguas de Latinoamérica, fue la experimentación con soportes mediáticos. Esto implicaba trascender lo meramente cinematográfico, aunque el universo audiovisual subyace y atraviesa las distintas trayectorias de desarrollo del laboratorio. Me interesaba promover la creación no solamente de películas, algo que ya desde hace décadas el Departamento de Comunicación ha consolidado como una de sus fortalezas, sino también obras en géneros transmedia e interactivos, así como ensayos fílmicos y piezas documentales expandidas que tocaran los horizontes de los soportes fotográficos, las publicaciones impresas y los medios alternativos. Esta inscripción de la práctica del laboratorio en una escuela de medios ha permitido incorporar intuiciones de la arqueología mediática y el arte en medios a la producción de obras documentales expandidas (ver Martínez Zárate, 2018), así como otras ramas teóricas que no necesariamente encuentran cabida en los institutos de cine.

Para cuando surgió la idea de crear el laboratorio, ya llevaba varios años desarrollando producciones digitales, interactivas y transmedia de manera independiente. IberoDocsLab fue el terreno donde experiencias e ideas desarrolladas en proyectos previos cristalizaron en una plataforma transversal de acción. Desde el inicio de mi producción, con casos como el proyecto transmedia Ciudad Merced (2013, ciudadmerced.mx), las preguntas que articularon mi práctica apuntaban a la misma línea esbozada en el párrafo anterior; esto es, una exploración sobre cómo distintos soportes mediáticos nos permiten traducir aspectos de una misma realidad según los medios con los que estamos trabajando. En este caso, por ejemplo, la pregunta fue qué aspectos del antiguo barrio de La Merced en la Ciudad de México (de nuestra decodificación del mismo) cabían 


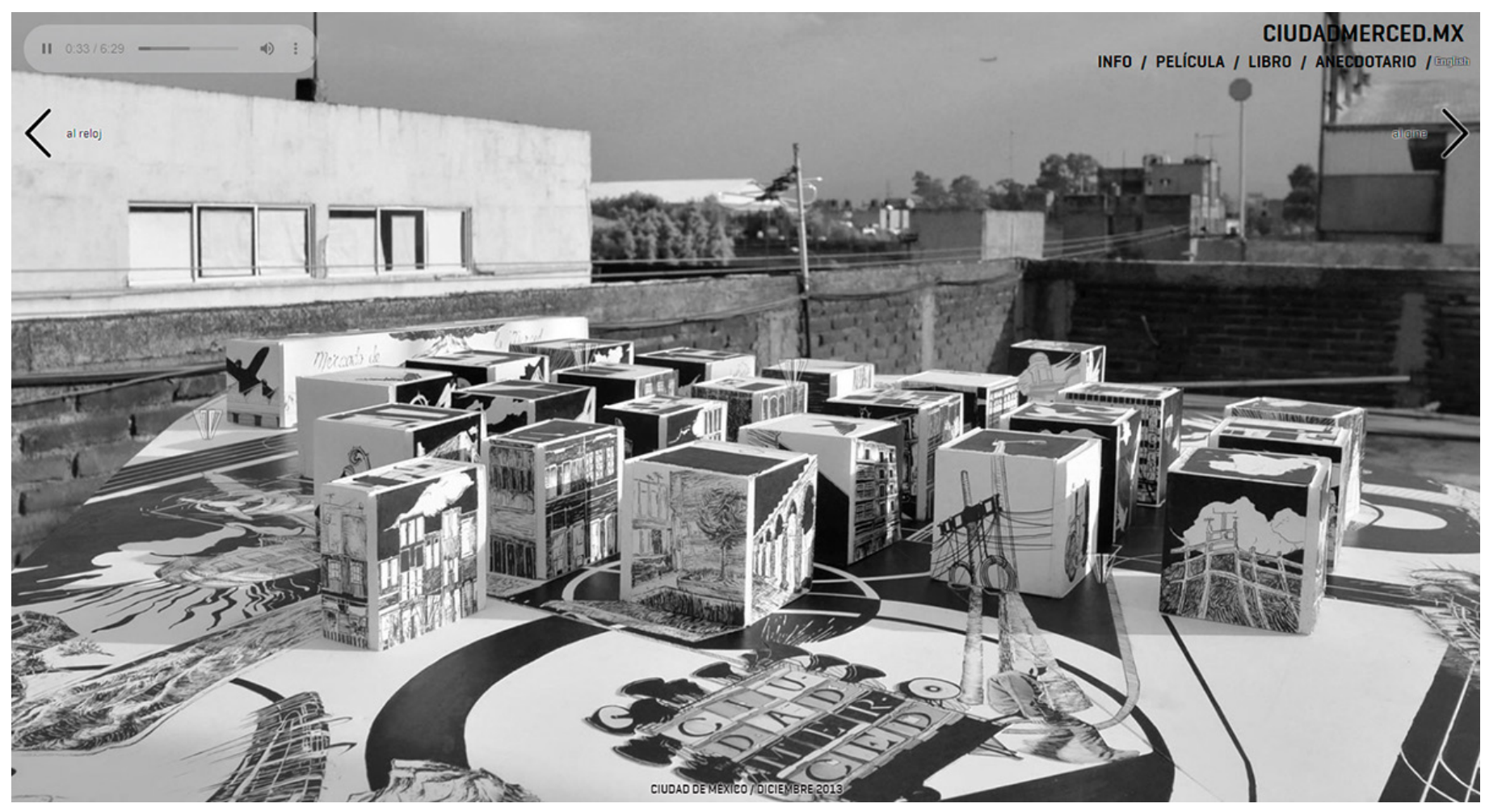

Figura 1. Captura de pantalla de web documental Ciudad Merced. Fuente: http://ciudadmerced.mx

en un libro, cuáles en una película y cuáles en un webdoc. Así, el webdoc tiene secuencias extrafílmicas que no tienen cabida en una película, como el uso de todos los fragmentos de las claquetas de uno de los días de rodaje para dar pie a uno de los 13 videos que nutren la narrativa digital. En cierto modo, la exploración transmedia permite tejer una cartografía de la expresión de naturaleza híbrida y, por lo menos desde su dimensión técnica, más compleja. Pongo énfasis en el aspecto técnico porque la complejidad en esta dimensión no necesariamente está presente en el nivel discursivo en las piezas finales. Hago una distinción consciente entre técnico y discursivo, pues las considero como dos dimensiones presentes en toda aventura narrativa. Por un lado, la dimensión técnica refiere a las herramientas y códigos con los que trabajamos, mientras que el discurso a los mensajes que buscamos compartir. Si bien la complejidad técnica en proyectos transmedia es casi evidente siendo que recurren a distintos soportes y códigos expresivos, la complejidad en el discurso no siempre es algo a lo que podemos aspirar e incluso, muchas veces, la experimentación en soportes múltiples busca precisamente todo lo contrario -simplificar el mensaje final, depurarlo.

Esto último es muy claro en Ciudad Merced, también en piezas como el webdocumental Santos Diableros (santosdiableros.mx) o el poema interactivo e instalación en sitio Poema Panorama (poemapanorama.net), donde existe un esfuerzo por depurar lo más posible el resultado mediante un manejo expandido de la técnica. Como si el dominio técnico y sus imbricaciones permitieran pulir los resultados. La idea anterior me parece que está condensada con claridad en las palabras del poeta y traductor Oswaldo Trujillo, contenidas en el componente impreso de Ciudad Merced:

Los Antiguos inventaron un orden canónico de las cosas: principio, medio y fin. A los modernos los antiguos siempre les parecieron fariseos y aburridos e inventaron nuevos órdenes. El problema es que lo moderno siempre envejece rápido. Si quieres representar algo, asegúrate de no olvidar que lo más sencillo es siempre lo más difícil de conseguir, que la belleza nada tiene que ver con el aburrido mármol de los antiguos, pero tampoco con el choteado esperpento de los modernos. La belleza es siempre la honestidad de la simpleza. (Trujillo, 2012, p. 31)

Varios puntos de esta cita me ayudan a explicar con más detalle los retos de un diseño transmedia y algunas de las ideas que a lo largo de estos años he ido esbozando en mis libretas.

La primera de ellas es la tensión constante que existe entre tradición e innovación, que Oswaldo ejemplifica en la dualidad antiguos-modernos. Toda innovación demanda una revisión de la herencia, y no hay modo de trascender las taras del pasado sin adentrarse primero en ellas. No sólo para "aprender de los errores", sino también de los aciertos. Uno de los aprendizajes que tenemos al alcance precisamente resuena con la idea de que "lo moderno siempre envejece rápido", o en otras palabras, los nuevos medios dejan de ser nuevos casi al momento de ver la luz. Esta problematización ha sido fundamental para las decisiones estéticas y narrativas implementadas desde las primeras obras interactivas y transmedia que realicé hasta la fecha. Guarda una estrecha correspondencia, además, con la discusión introducida en el apartado anterior sobre el des- 


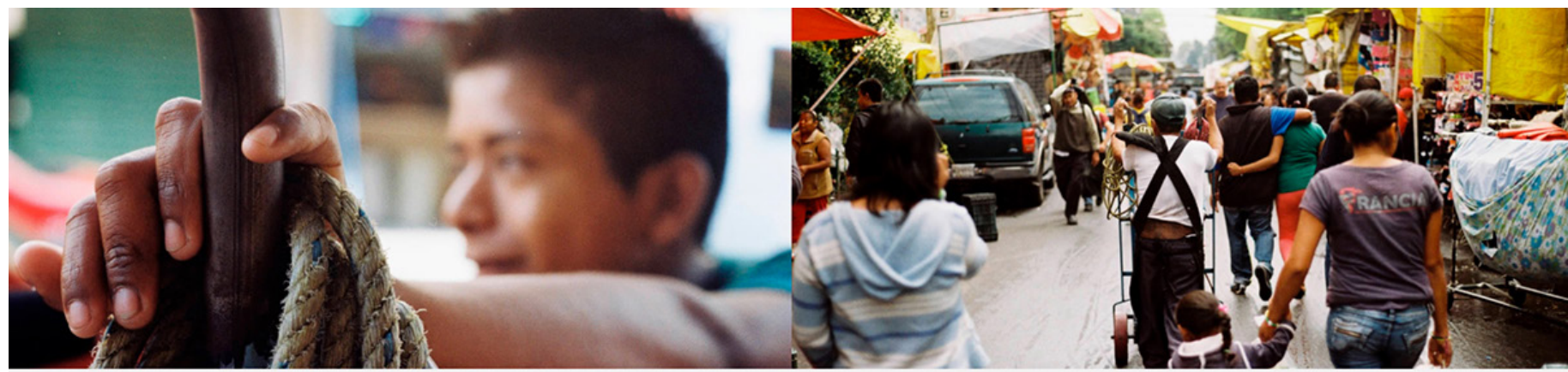

SANTOS DIABLEROS

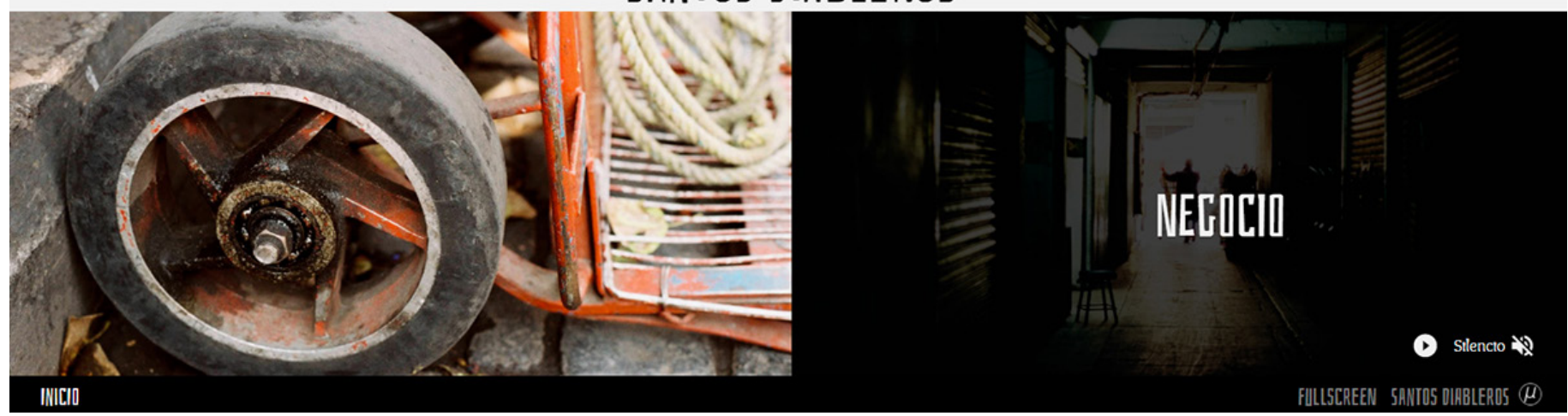

Figura 2. Captura de pantalla del webdocumental Santos Diableros. Fuente: http://santosdiableros.mx/

pliegue constante de una dialéctica crítica de la apropiación tecnológica.

Un ejemplo concreto de esta idea está presente en el proyecto temprano Santos Diableros, webdocumental diseñado en esencia con puras fotografías fijas, audio de entrevistas y textos explicativos, con la intención de convertir esta narrativa en un modelo replicable fácilmente en contextos de poca penetración tecnológica, ya fuera mediante talleres ${ }^{3}$ o la promoción de su uso. Para tal efecto, liberamos el código web con instrucciones, de tal manera que cualquier persona que quiera tomar esta arquitectura de navegación es libre de hacerlo. Por la misma razón, el código está publicado con instrucciones claras para que incluso quienes no tengan conocimientos técnicos de diseño y programación web puedan crear sus propias narrativas digitales con esta misma estructura.

Lo anterior refleja una postura de diseño regida por la economía de recursos, hacer más con menos, y que está presente en muchas de mis producciones. Evoca el sitio de enunciación compartido en la sección inaugural de estas páginas, pues busca integrar sistemas de producción acordes con la realidad de producción de México y Latinoamérica. Esto se ha trasladado no solamente a las piezas autorales desarrolladas de manera independiente, sino también al trabajo impulsado desde el Laboratorio Iberoamericano de Documental como un espacio que no tiene un presupuesto asignado por la universidad. Un caso de esto son las producciones desarrolladas con un acervo fotográfico que retrata el movimiento estudiantil de 1968 en México, perteneciente al diario El Heraldo de México y donado a la universidad en $2017^{4}$. Con las fotografías, tra- bajamos dos piezas con esquemas de producción totalmente distintos. La primera de ellas es un filme-ensayo titulado El monopolio de la memoria y la segunda, El cuerpo es un archivo. Juego para diez cámaras, una video instalación para una pantalla $360^{\circ}$ de 18 metros de largo y 2 de altura, comisionada para la colección permanente del Museo Ciudadanías en Movimiento, perteneciente al Centro Cultural Universitario Tlatelolco de la Universidad Nacional Autónoma de México, la cual también vive como una versión en video $360^{\circ}$ disponible en Vimeo (https://vimeo.com/470175237). El caso de estas dos piezas es muy representativo puesto que ejemplifica, por un lado, un concepto que he propuesto como mecanismo de intervención del archivo: el archivo como acontecimiento, que hace referencia a la necesidad de activar el archivo como estrategia para abrir la lectura de los hechos a múltiples interpretaciones 5 . Por otro lado, porque mediante dos lógicas completamente distintas, se atendieron las necesidades de producción de cada una de las piezas. Confirma que una investigación artística puede ser transmedia al conectar distintos proyectos y procesos de obra, algo que intentaré desarrollar un poco más con las intuiciones metodológicas que dan cuerpo a la sección final de este artículo.

Para el caso de El monopolio de la memoria, no se contó con presupuesto salvo por un modesto fondo de investigación que se aplicó para un asistente de investigación y el coguionista. Este fue el primer caso de apoyo directo a IberoDocsLab de parte de la División de Investigación y Posgrado de la universidad, abriendo así más posibilidades para el desarrollo de investigaciones artísticas dentro de la institución. Para ello, por supuesto, fue necesario someter un protocolo de inves- 
tigación mediante convocatoria. El desarrollo de proyectos transmedia bajo el esquema de proyectos de investigación, ha permitido ampliar el alcance de las producciones del laboratorio. Al mismo tiempo, desde IberoDocslab hemos buscado promover el reconocimiento interno de la figura del investigador-artista como parte importante del claustro universitario en un Departamento de Comunicación ${ }^{6}$, un campo con un desempeño práctico innegable.

En cuanto a la composición audiovisual de la película, la complejidad de trabajar con un acervo de fotografía fija para una narrativa en movimiento, se tradujo a una economía discursiva que mediante una voz en off, reencuadres y desplazamientos en las imágenes, y una selección musical que siguió dos premisas (la intensidad emocional y la pertinencia histórica), tuviera como resultado una pieza compacta que cuestiona no la historia de los acontecimientos, sino sus modos de narración. La película tuvo un circuito de exhibición en México, con algunos reconocimientos, y en la actualidad se encuentra disponible en FilminLatino. En contrapunto, El cuerpo es un archivo. Juego para 10 cámaras, al ser una comisión para una infraestructura de proyección $360^{\circ}$ con 6 proyectores, suponía un diseño narrativo que se ajustara a estas condiciones técnicas así como al contexto de su relación con el público (un museo de arte y memoria). El discurso, además, fue totalmente contrario: si la película recurrió a la voz en off y la reflexión ensayística intercalada con largas secuencias musicales, la instalación buscaba detonar lo que denomino una reflexión encarnada, desde los cuerpos, la piel, los afectos. Así, se convocó a una colaboración con la Sociedad de Carne y Hueso, un colectivo de danza butoh. Las reglas de este "juego" fueron las siguientes: dentro de un foro de cine, una caja con 60 fotografías esperaba que una a una, las integrantes del colectivo fueran sacando las fotos, mostrando cada imagen a la cámara que entre las diez que registraban la activación estaba destinada para ello, para luego acercarse al grupo y colectivamente reaccionar con el cuerpo a la imagen. Este acontecimiento duró unas 3 horas de grabación ininterrumpida y en su montaje final consiste de una pieza de 15 minutos donde conviven múltiples pistas de las 10 cámaras (digitales, 8 mm, 16 mm, 35 mm y 120 mm). Una vez concluida, se desarrolló una adaptación para video $360^{\circ}$ que puede consultarse en Vimeo?.

El cuerpo es un archivo es una pieza significativa también porque ilustra uno de los modos en que he intentado fortalecer la plataforma de producción del laboratorio, llevando la realización de comisiones solicitadas a mí como creador, al espacio colectivo de IberoDocsLab. Otros ejemplos de esquemas de producción semejantes son la memoria interactiva para el 1er Encuentro de Narrativas Documentales

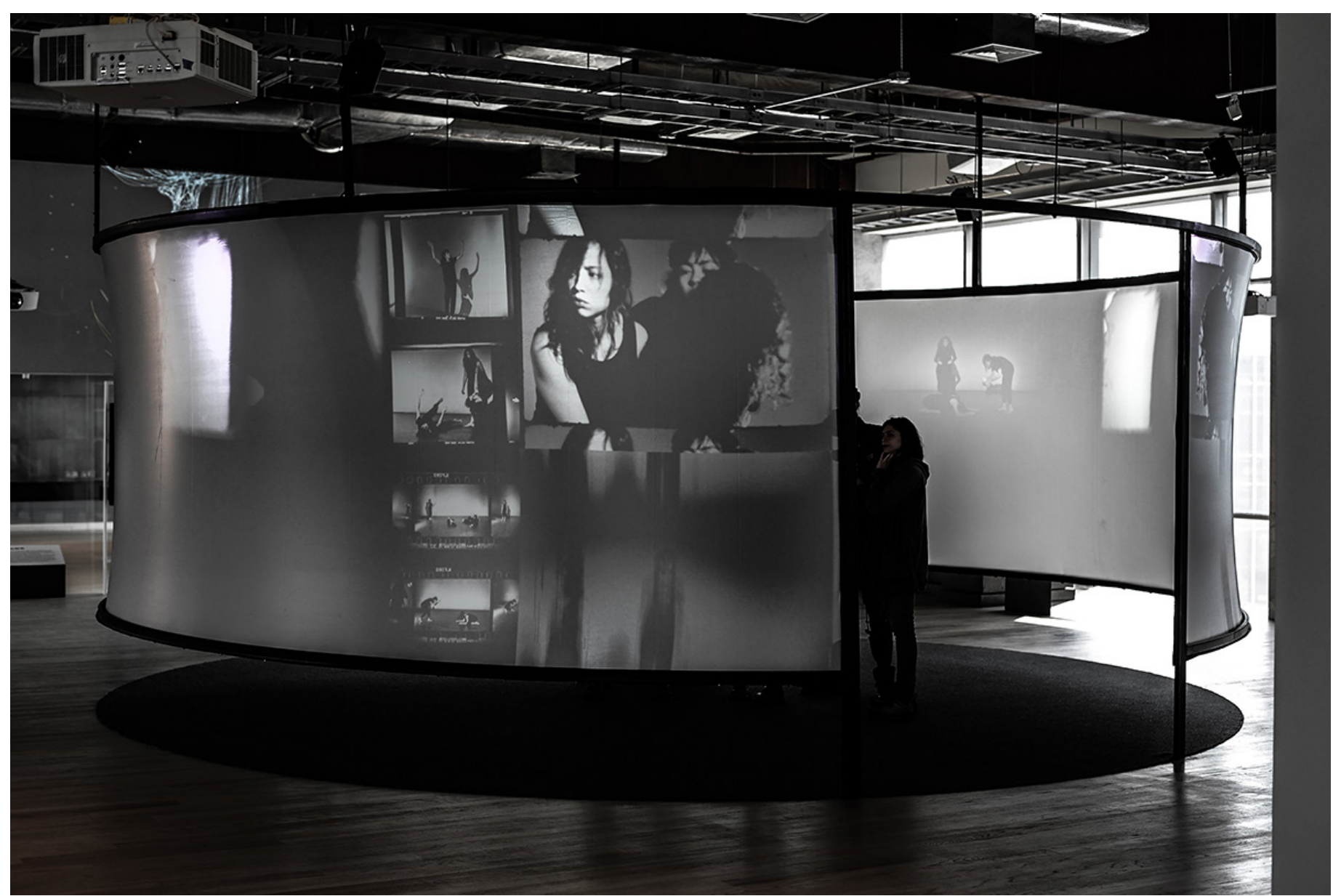

Figura 3. El cuerpo es un archivo. Juego para diez cámaras, en el M68. Ciudadanías en Movimiento. Fuente: https://pablomz.info/ cuerpoarchivo. 


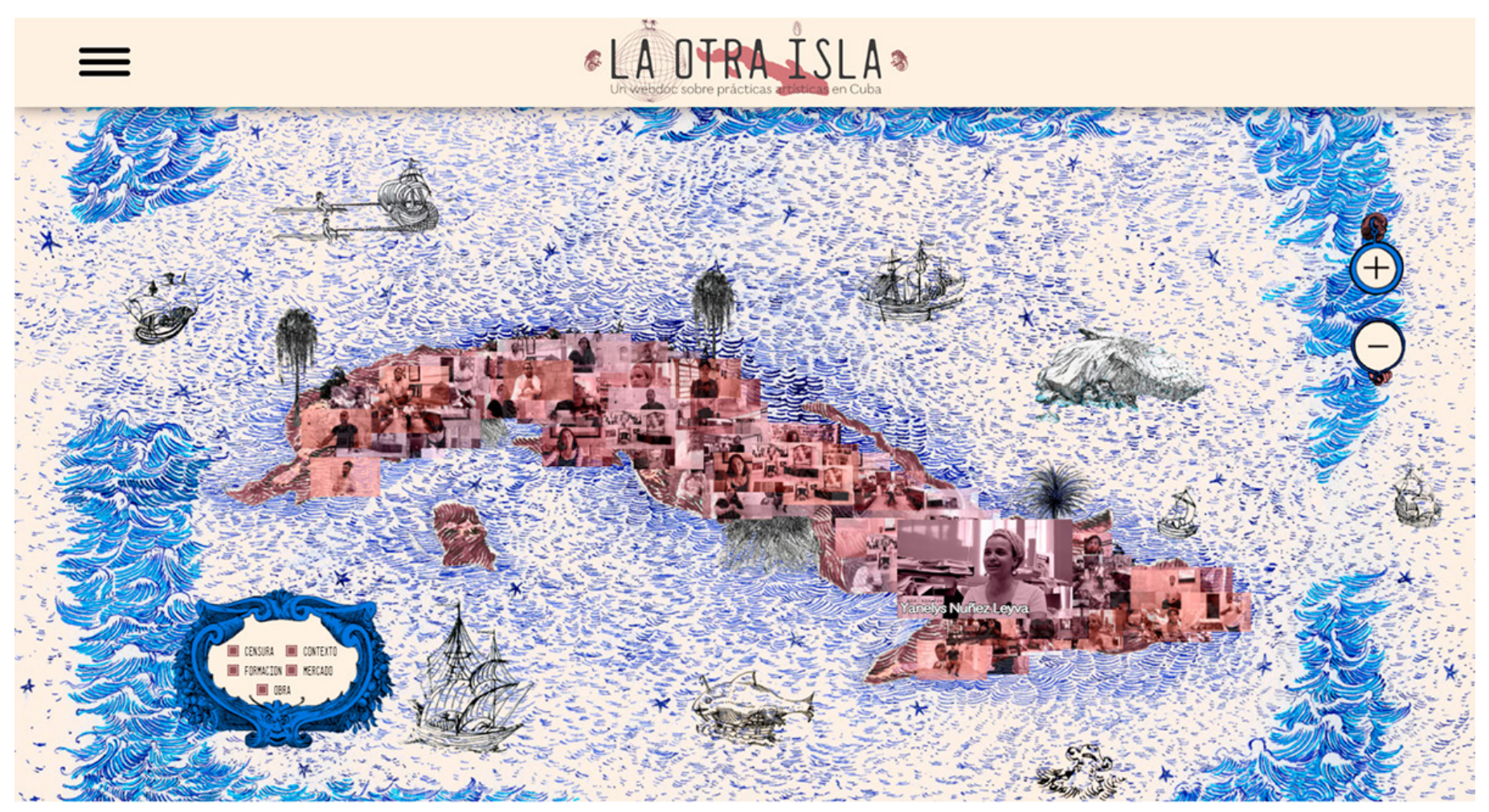

Figura 4. Captura de pantalla del webdoc La otra isla. Fuente: http://www.laotraisla.net

Transmedia organizado por el Canal 22 en México ${ }^{8}$, o el recién estrenado Forensic Landscapes (forensiclandscapes.com, 2020), proyecto dirigido por Anne Huffschmid que retrata el trabajo de científicos forenses y familiares de personas desaparecidas en México, Guatemala y Argentina. Este último fue una coproducción entre IberoDocsLab y la Freie Universitat de Berlín que representó un gran reto investigativo a nivel estético. El proyecto obtuvo reconocimiento internacional, lo que confirma que las soluciones técnicas a las que llegamos para traducir la vastísima y muy compleja investigación de Anne en una suerte de archivo-paisaje inmersivo, rindieron frutos. Un esquema semejante se implementó en una coproducción con la firma mexicana Aura (auracultura.com), con apoyo de Open Society Foundations, para la realización de un documental multiplataforma titulado La otra isla, que revisa la relación entre producción artística y censura en Cuba mediante una exposición, un documental lineal y un archivo interactivo que entreteje testimonios de artistas, curadores y personalidades de la escena cubana mediante temáticas concretas. El tema de las comisiones es siempre un reto pues implica conciliar distintos intereses sin sacrificar las búsquedas narrativas de corte crítico que hemos descrito anteriormente. Tal fue el caso de Momento MX (momentomx.com, 2016), un documental interactivo con un presupuesto bastante decente que buscó retratar distintas industrias creativas en México bajo la lógica de una serie interactiva, que al final sólo quedó en los dos episodios iniciales a raíz de la disolución de la empresa que comisionó la obra.

Los esquemas de producción varían y se van ajustando según las posibilidades de cada proyecto. Tanto un diseño basado en la economía de recursos como la diversidad en esquemas de producción son indispensables en un escenario donde los apoyos para el desarrollo de proyectos transmedia son muy escasos, aunque cada vez parecen ganar más terreno. De ahí que el impulso dentro de la Universidad Iberoamericana como una fuente de financiamiento de proyectos sea fundamental para ampliar las posibilidades de realización. Al mismo tiempo, refuerza el enfoque de investigación artística que ha sustentado los proyectos creados tanto dentro como fuera de IberoDocslab, pues permite pensar el desarrollo artístico como una práctica transversal que conecta proyectos entre sí y cuyos fines principales no son la solvencia económica de los proyectos sino las preguntas de investigación y su aporte a la realidad.

Vale la pena citar dos proyectos recientes realizados con apoyos de la División de Investigación y Posgrado de la Universidad Iberoamericana a partir de convocatorias extraordinarias vinculadas con el sismo de 2017 en la Ciudad de México y la pandemia por Covid-19 en 2020. El primero de ellos, La memoria se filtró por una grieta, comprendió un programa de talleres, documentados en un cuadernillo impreso, un sitio web a modo de teaser de la película, y una película que está siendo concluida en la actualidad debido a los grandes retos narrativos que supuso su estructura de ensayo. En concreto, de este proyecto vale resaltar la vinculación comunitaria como una premisa de creación (presente en el trabajo en el Barrio de la Merced ya citado, por ejemplo). Asimismo, el enfoque ensayístico en la producción fílmica e interactiva, un campo subdesarrollado en el panorama narrativo de México que, desde mi perspectiva, conecta muy estrechamente con el 
potencial que IberoDocsLab tiene como un laboratorio situado dentro de una universidad, puesto que permite conducir las investigaciones en el ámbito académico a otros medios y soportes para la producción y divulgación del conocimiento. El otro proyecto, Enfermería Visible, Enfermería Invencible, tiene como centro resaltar el trabajo de profesionales de enfermería como principal frente de cuidado y acompañamiento de pacientes hospitalizados por Covid-19 mediante un podcast, un cortometraje documental y un cómic. En concreto, además de las dificultades de producción que implicó este proyecto por su realización en un contexto de distancia social y alto riesgo, cabe resaltar la colaboración con un grupo amplio de profesionales de enfermería representados por la Red de Enfermería Mexicana, desplegando un diálogo interdisciplinar complejo que puso a prueba la capacidad de adaptación de nuestros modelos de producción. Es muy importante resaltar que en prácticamente todos los proyectos que he realizado en mi carrera he involucrado a estudiantes o exalumnos en la realización, con su justa retribución económica. Este aspecto ha fortalecido el valor de lberoDocsLab al interior de la comunidad universitaria, convirtiéndose en un espacio no nada más de formación y reflexión, sino también de desarrollo profesional.

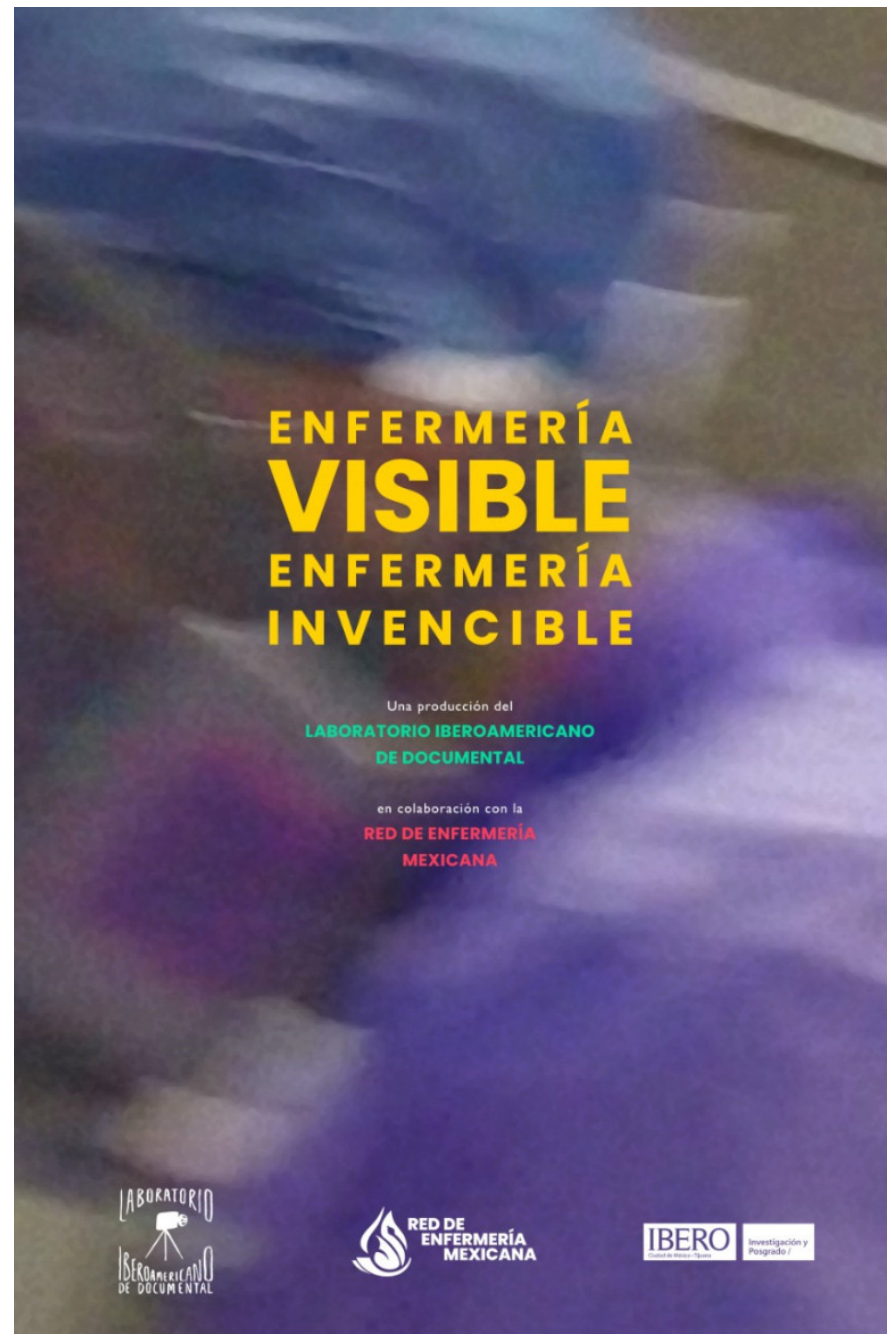

Figura 5. Cartel Enfermería visible, enfermería invencible. Fuente: https://iberodocslab.org
Finalmente, un proyecto que resume bien los principios de diseño que he seguido en estos años es Disecciones sobre planos. Ensayo(s) desde Tlatelolco, que fue un proyecto sumamente personal en su concepción y tejido, pero que implicó la colaboración con distintas instancias. El proyecto explora una región en la Ciudad de México que ha sido muy importante a lo largo de la historia, desde la época prehispánica hasta la modernidad. Fue la ciudad hermana de Tenochtitlán, el último bastión de resistencia contra los españoles, sede de la primera universidad de América, así como sitio de desarrollo de uno de los proyectos de arquitectura social más importantes de la modernidad, donde en cuya Plaza de la Tres Culturas, sucedió la infame matanza de estudiantes en 1968. Disecciones sobre planos despegó con una invitación para hacer una residencia artística en torno a una maqueta del conjunto urbano Nonoalco-Tlatelolco, como parte de una iniciativa de Tlatelolco Central, con sede en Central de Maquetas. La exploración inicial coincidió con el lanzamiento de la primera beca de gobierno en México para narrativas transmedia, presentada por el Fideicomiso para la Promoción y Desarrollo del Cine Mexicano en la Ciudad de México (Procine); éste ha sido el único fondo público al que he aplicado en mi carrera, con cuya obtención pudimos finalizar el proyecto. Simultáneamente, tomé la decisión de enclavar este proyecto en IberoDocsLab en seguimiento al espíritu descrito anteriormente, el cual busca integrar procesos de investigación artística y producción de conocimiento en el contexto de la universidad. Además de contar con este esquema híbrido en su diseño de producción, presenta también una combinación de estrategias técnicas y discursivas con fines de experimentación en distintos soportes mediáticos.

Disecciones sobre planos. Ensayo(s) desde Tlatelolco es uno de los proyectos con más salidas de todos los desarrollados hasta el momento. Incluye un libro, un webdocumental (con textos, videopoemas y ensayos $360^{\circ}$ ), una instalación itinerante en VR y un performance de cine expandido, así como una instalación adaptable a contextos de exhibición. Cabe resaltar que la integración de soportes análogos y digitales, búsqueda presente desde trabajos tempranos como Santos Diableros, fue un eje central que fusionó las exploraciones técnicas con los fines discursivos del proyecto. Además de componer los videopoemas con filmaciones en súper 8 sometidas a distintos procesos fotoquímicos para reflexionar sobre el mismo desgaste de esta zona de la ciudad y los ideales de modernidad, el material fotoquímico, junto con recortes de archivo, habitan una composición inmersiva que nutre los ensayos $360^{\circ}$ y la instalación en realidad virtual. Finalmente, otro aspecto importante de este proyecto, también presente en otros como Poema Panorama, fue llevar la narrativa digital a una instalación física. Parece que la materialización de los proyectos digitales, su montaje en el espacio físico, permite no solamente llegar a una mayor audiencia y conectar con otras comunidades; al mismo tiempo, fomenta lecturas alternativas de la realidad analizada, como si la iteración de una pieza 


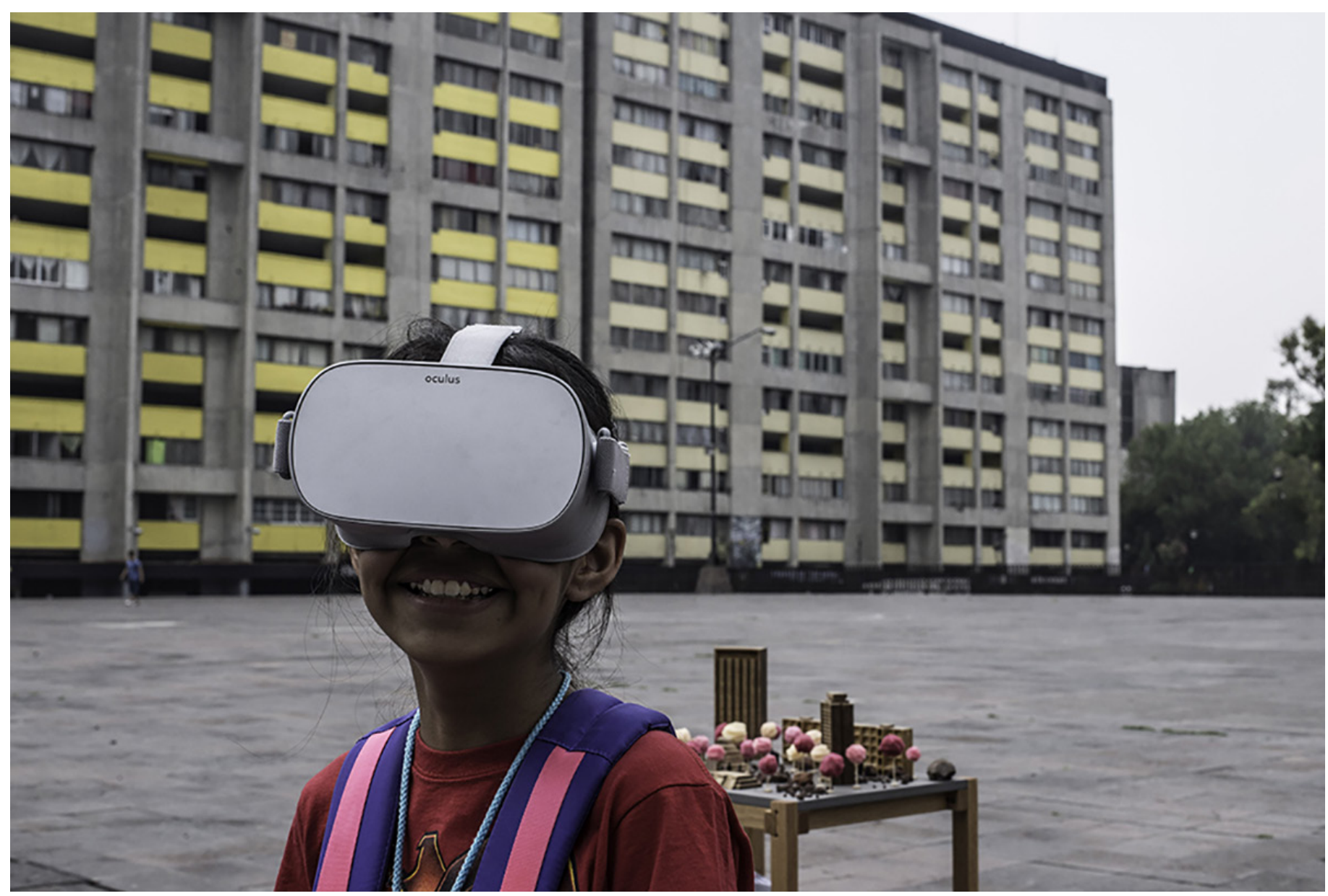

Figura 6. Instalación VR en la Plaza de las Tres Culturas. Fuente: elaboración propia.

fuera capaz de ampliar sus resonancias discursivas e interpretativas.

Este recorrido por fragmentos de algunos de los proyectos realizados en la última década tuvo la intención de esbozar algunas de las ideas que han guiado mis exploraciones, a su vez erráticas. Cabe señalar que la apropiación crítica de la tecnología, en todos los casos, ha partido del desarrollo de una librería propia de códigos de interacción audiovisual que han mutado para nutrir otras piezas más recientes y en producción al momento. La adaptabilidad en los modos de diseño y las soluciones tecnológicas y narrativas, la voluntad de resolver con los recursos al alcance, la iteración de piezas en formatos y espacios distintos, así como la diversificación de estrategias de realización y flujos de trabajo, son algunas de las formas en que he articulado mi práctica documental dentro y fuera del Laboratorio Iberoamericano de Documental. En el siguiente apartado, intentaré enmarcar estas reflexiones dentro de notas metodológicas que den un poco más de forma a este bricolaje de creación.

\section{Montaje expandido: intuiciones metodológicas para la práctica documental transmedia}

Entre las ventajas de emparejar la labor de investigación y docencia con la labor de creación, está la posibilidad de reflexionar de manera sistemática sobre la propia práctica y organizar las ideas en retrospectiva y prospectiva -esto es, llevar a cabo revisiones críticas del trabajo realizado y aplicar intuiciones de diseño a futuras producciones en función de los aprendizajes. En los últimos años he desarrollado algunas intuiciones metodológicas que aplico más o menos libremente para proyectos de carácter documental. Antes de proceder al esbozo de dos modelos metodológicos, me permito plantear algunas intuiciones generales que de algún modo atraviesan toda mi práctica.

El marco general de mis procesos de investigación artística, en su inspiración crítica, recupera no sólo la tradición del cine crítico latinoaméricano, sino también aspectos teóricos de la comunicación alternativa, la comunicación para el desarrollo y la pedagogía crítica de la región. Entre los distintos conceptos que he incorporado, el que más me ha ayudado a organizar los procesos de investigación artística (tanto aplicado en retrospectiva como, una vez apropiado, en el diseño de nuevos proyectos) es el de investigación temática de Paulo Freire. De acuerdo al pedagogo, la investigación temática es una herramienta útil para la educación problematizadora -aquella que parte de la identificación de problemas de la realidad y gira en torno al abordaje de los mismos. La investigación temática consiste en la organización del universo de realidad que 
estamos investigando -los problemas que abordamos, en términos de Freire- en temas que los constituyen. Al dividir los fenómenos de la realidad en distintos temas, podemos organizar mejor la exploración y profundizar en nuestra investigación. Este es un proceso orgánico que debe adaptarse a las condiciones de la realidad, por lo cual las temáticas nunca se agotan de antemano y hay que irlas descubriendo a lo largo de la exploración.

La investigación temática, que se da en el dominio de lo humano y no en el de las cosas, no puede reducirse a un acto mecánico. Siendo un proceso de búsqueda de conocimiento, y por lo tanto de creación, exige de sus sujetos que vayan descubriendo, en el encadenamiento de los temas significativos, la interpretación de los problemas. (Freire, 1970, p. 134)

Las problemáticas no son solamente de carácter social (o sociológico), sino también pueden ser de carácter expresivo (técnico o discursivo). En el diseño de proyectos, recurro a la investigación temática como la primera (y última) brújula, en un esfuerzo casi cartográfico para trazar mapas de posibles rutas para la realización de los proyectos. La investigación temática la he vinculado también con otras técnicas que estructuran los procesos de investigación artística, prácticas principalmente de inspiración arqueológica.

Toda práctica documental implica trabajar con registros múltiples, en ocasiones de procedencias varias (algunas ya contenidas en otros archivos), e invariablemente un proyecto documental (y en gran escala un cuerpo de obra) constituye un archivo en sí mismo, una arquitectura documental, un sistema de relaciones que supone el trabajo de asociaciones espaciales y temporales con este material. Parece natural que una cartografía temática se auxilie de técnicas de catalogación y organización del universo documental. Gabriela Giannachi, en su libro Archive Everything. Mapping the Everyday, nos brinda algunas pistas de estrategias metodológicas para abordar nuestros archivos.

Una arqueología del archivo, hablando metodológicamente, consiste en la adopción de un cuerpo de estrategias que permite mirar al archivo como una multiplicidad de puncta, o detalles, que deben ser tratados como índices marcando relaciones espaciales y temporales entre el pasado y el presente, donde, en el contexto de una economía digital, son también moldeados por los medios que les dan forma. La prospección arqueológica, el registro arqueológico y la estratigrafía son entre las herramientas que tenemos para facilitar la orientación dentro del cúmulo de materiales que forman el archivo, los puncta, tanto espaciales como temporales. (Giannachi, 2016, p. 35) ${ }^{9}$

Estas técnicas nos hablan de niveles de trabajo con los soportes que utilizamos a nivel técnico, pero también de los mensajes o el discurso que buscamos comunicar. Con ellas trabajo a nivel de estructura y seguimiento de los proyectos.
A partir de las mismas, he ido conceptualizando un modo de organizar los conjuntos de registros con los que se trabaja en proyectos transmedia.

Dentro de mi propuesta de crítica práctica de la comunicación (Martínez Zárate, 2018 y 2021), he conceptualizado una dimensión operativa de creación de relaciones mediante las técnicas ya descritas, entre otras más, como poética de la información. Entiendo a ésta como la capacidad de crear relaciones significativas entre los elementos que conforman la realidad con la que estamos trabajando. De algún modo, la poética de la información trabaja con desgloses y análisis de la realidad circundante, con los "problemas" a los que hace referencia Freire y las temáticas o unidades de sentido que la configuran, y despliega mecanismos de reorganización de esa realidad a partir de crear relaciones entre sus componentes. En este sentido, la poética de la información es esencialmente una práctica de montaje, de reorganización del mundo, parafraseando a Vertov.

Esta reorganización del mundo, en el sentido operativo, la he trabajado desde lo que denomino un sistema modular de diseño narrativo. Este sistema organiza la materia narrativa en distintos niveles, evocando la estructura organizativa de los diagramas de Venn. En el nivel más amplio tenemos el universo narrativo, que se refiere al horizonte de realidad dentro del que se desdobla un proyecto. Este universo narrativo tiene posibilidades infinitas de relación, temáticas diversas y múltiples relaciones posibles entre los elementos que lo configuran. En este sentido, es necesario trabajar con grupos de elementos para poder navegar los laberintos de nuestros proyectos. Así, dentro del universo narrativo existen módulos narrativos, conjuntos de elementos que pueden hacer referencia a temáticas del discurso, a soportes, a momentos de la investigación, entre otras aplicaciones. Este sistema es modular porque además de dividirse en bloques dinámicos, se adapta, es cambiante, y nos auxilia en distintas etapas del proceso, desde la investigación y el desarrollo hasta su acabado y circulación. Una de las aplicaciones que todavía estoy desarrollando con más detalles es la transformación de este sistema modular de diseño narrativo en un sistema modular de catalogación y preservación de arte en medios, donde los módulos y los elementos subsecuentes sean de utilidad para generar un acervo de obra que nos sirva para organizar, preservar y difundir proyectos que viven en distintos soportes mediáticos.

Los módulos están compuestos a su vez por unidades narrativas. Las unidades corresponden a las manifestaciones concretas que nutren nuestro universo narrativo. Éstas pueden ser del tipo temático o discursivo, así como técnico o de soporte. Las unidades pueden ser videos, textos, audios. Pueden ser también personajes, lugares, momentos. Pueden ser registros tan variados como se imagine, y en proyectos transmedia, podrían servir para articular cada una de las salidas 
- por ejemplo, módulo película, módulo libro, módulo webdoc, módulo podcast, etc. En este sentido, podemos construir relaciones a modo de fractal: un módulo puede tener las unidades que a su vez son módulos que contienen otras unidades en un nivel más detallado de la estructura. De este modo, nos permitimos organizar toda la producción de manera escalonada y distribuida en las distintas etapas de realización. El componente nuclear de este sistema, por supuesto, está en el tejido de las relaciones que se articulan entre unidades, y entre módulos, la poética de la información trabaja en torno a las arquitecturas posibles de este universo fractal de módulos y unidades narrativas.

De manera paralela al diseño modular, los procesos de investigación los he organizado bajo la premisa de lo que puede o no llegar a ser parte de una narrativa documental. Esto me ha ayudado a definir qué aspectos nutren el universo narrativo con el que estoy trabajando y hacia dónde puedo conducir la investigación. Este siguiente modelo me ayuda a dar cierre al presente texto, pues articula algunas de las nociones que he ido tejiendo en esta amalgama de intuiciones.

Este modelo surgió al preparar un taller sobre escritura y dirección de webdocs en la Universidad de las Artes de Zurich como parte del congreso Cilect 2017, combinando un análisis retrospectivo de los proyectos desarrollados hasta ese punto de mi carrera con procesos en curso en ese entonces (ver Figura 7). El modelo funciona mediante tres niveles de operación transversales que, podría decir, son las tres dimensiones operativas que rigen todo mi trabajo -investigación, escritura y montaje- los cuales están siempre en retroalimentación perpetua y trascienden los horizontes de los proyectos. Esto último implica que los procesos de escritura, investigación y montaje permiten articular no solo proyectos aislados, sino que contectan distintos proyectos entre sí como parte de un cuerpo de obra y una investigación de vida.

Este modelo está organizado como una dinámica de tensiones entre fronteras de realidad. Más allá de la frontera final se extiende al infinito la dimensión de realidad desconocida, la cual inevitablemente impondrá límites sobre nuestro conocimiento y capacidad. Así, la primera actividad consiste en el reconocimiento de los límites en nuestras posibilidades de exploración de la realidad, incluyendo preguntas del tipo técnico y operativo, también éticas y políticas. Este primer momento de reconocimiento del horizonte cognoscible, que no es otra cosa que el reconocimiento de los límites de partida, desde mi perspectiva resulta fundamental en el desarrollo de proyectos transmedia, pues nos permite situar críticamente nuestras posibilidades de realización dentro de un horizonte de realidad cualquiera. Al interior de este primer horizonte de cognición, que por supuesto involucra toda forma de conocimiento sensible e inteligible disponibles en un tiempo y espacio determinados, se despliega un horizonte de realidad documentable.

Una vez vislumbrado el horizonte de conocimiento, que se va transformando conforme nos adentramos en la investigación, aquello que vamos conociendo eventualmente lo reconoceremos gracias a la existencia de distintos registros de experiencia (y la posibilidad no sólo de apropiación e intervención de dichos índices de realidad, sino también de su creación). Muchos de los registros que acumulamos a lo largo de la investigación, ya sea por recolección o por inscrip-

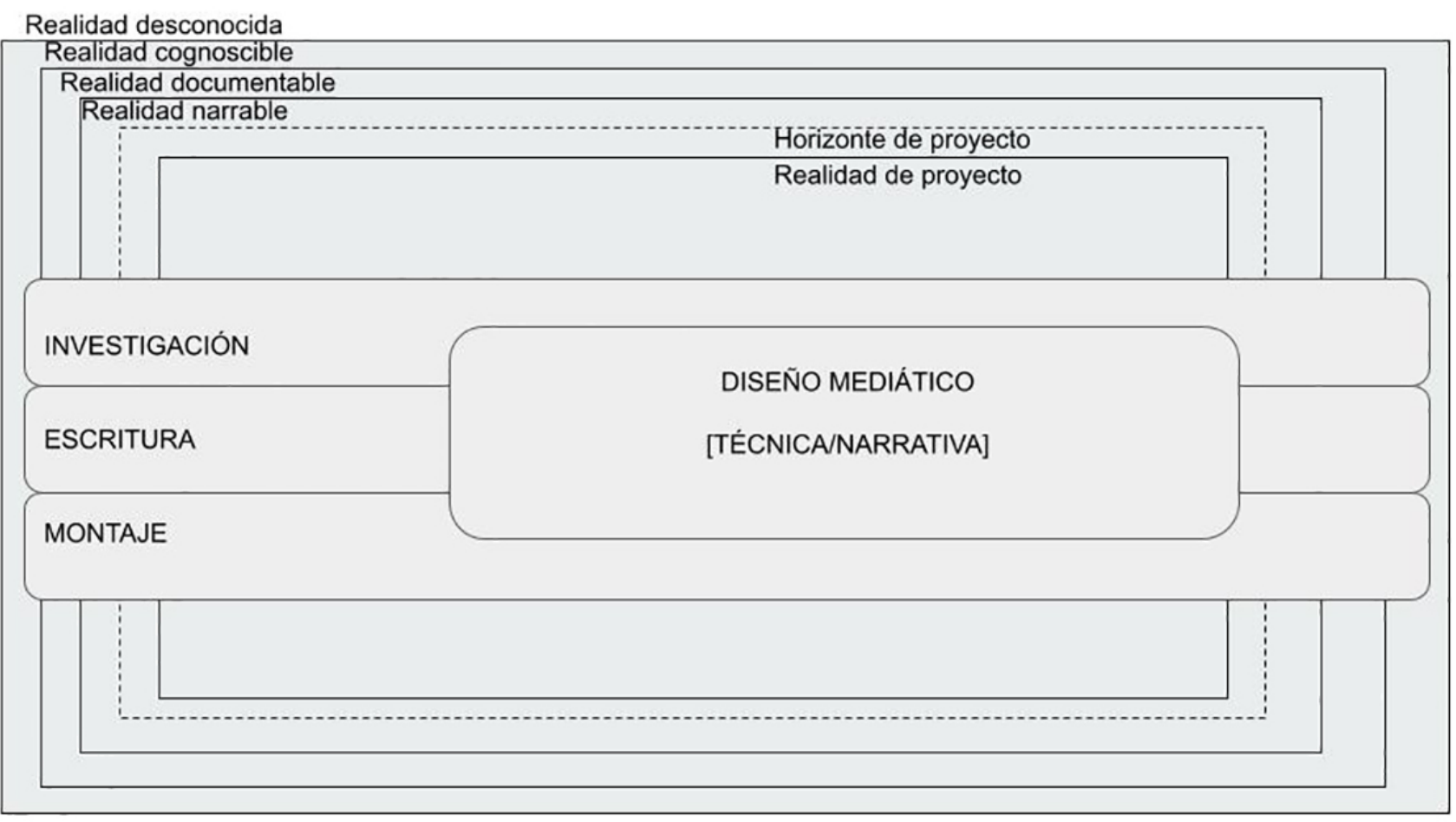

Figura 7. Modelo de desarrollo de proyectos documentales. Fuente: elaboración propia. 
ción (por producción de imágenes, sonidos), quedarán fuera del horizonte del relato, pues no son traducibles a modos de narración; en esas tensiones entre experiencia sensible-inteligible y documentación, se traza la siguiente frontera, entre el horizonte inaugural de conocimiento y el horizonte de documentación.

La realidad documentable nos habla de aquellos aspectos que podemos registrar en cualquier soporte tecnológico, según los recursos y capacidades a nuestro alcance. De este universo documental que vamos configurando para un proyecto, e inclusive de su conexión con otras experiencias de producción propias y ajenas (por ejemplo, materiales sobre la misma temática que hemos levantado en otros momentos con fines distintos o materiales de archivo que vamos encontrando y resituando en la esfera de nuestra producción), surge el archivo de investigación de un proyecto documental. Como mencioné, no todo lo que pertenece a este archivo de proyecto, al universo de registros que lo comprenden, está sujeto a convertirse en parte de la narración o del relato que estamos tejiendo. La realidad narrable es aquello que podemos enunciar, comprende una manifestación, de ahí su potencia política. En gran medida, es el punto donde el tejido de relaciones encuentra su operación más fina, que si cruzamos con el esquema modular, es donde vemos que las unidades y módulos comienzan a entretejerse en una arquitectura de la expresión.

En la dimensión de la realidad narrable vive nuestro proyecto documental y su potencia expresiva. La última frontera de realización es una frontera dinámica y permeable entre el horizonte de proyecto y la realidad de un proyecto. El horizonte de un proyecto contiene todas las posibilidades técnicas y discursivas de nuestra empresa creativa, mientras que la realidad del proyecto condiciona dicho horizonte de posibilidades según los recursos con los que al final contamos y los obstáculos que fuimos sorteando en el camino.

Las tres dimensiones operativas de montaje, escritura e investigación, son los instrumentos con los que trazamos las rutas desde la esfera de lo cognoscible a la realidad final del proyecto, pasando por el documento y el relato, hasta terminar en su inserción en la esfera de lo público y, ultimadamente, nutrir nuestro propio cuerpo de obra. En este último momento, es donde el archivo de un proyecto pasa a formar parte de un archivo mayor que comprende todas las otras investigaciones hechas para otras piezas. Investigaciones que viven de imágenes, sonidos, textos de muy diversa temática y soporte, de desarrollos tecnológicos y de estrategias de diseño, libretas, notas, guiones y carpetas, así como de metodologías móviles como las resumidas en este apartado. Dentro de la esfera de mi práctica, la investigación, la escritura y el montaje como dimensiones operativas transversales, comienzan y continúan más allá del horizonte de un proyecto. Lo anterior implica que los procesos de investigación artística conectan proyectos entre sí y van dando forma a un cuerpo de obra diversa, a un archivo en múltiples soportes y con condiciones distintas de conservación. De ahí la urgencia de traducir las metodologías de producción en un modelo modular de catalogación y preservación del arte en medios.

Estas tres dimensiones, dentro del último modelo comentado, se articulan metodológicamente en lo que podemos englobar como diseño mediático, una operación de condensación y cristalización de los procesos en las manifestaciones concretas que dan forma a un proyecto, y que consta de la combinación de una dimensión técnica (manejo de medios y lenguajes) con una discursiva (intenciones comunicativas y mensajes). La investigación y la escritura se llevan a cabo tanto de manera sistemática en espacios destinados para cada proyecto, como en las libretas o diarios de creación que soportan la práctica.

Investigación, escritura y montaje son cualidades de la imaginación, lo que supone que la práctica documental, en su exploración de la realidad, es necesariamente una búsqueda constante por la reimaginación del mundo, una ¡muerte a lo real! Ursula K. Le Guin habla de "hacer mundos" como un rasgo de toda práctica artística:

En cualquier caso, lo que hacen los artistas es crear una selección particularmente hábil de fragmentos del cosmos, piezas inusualmente útiles y entretenidas, escogidas y dispuestas para dar una ilusión de coherencia y duración en medio del flujo incontrolable de eventos. Una artista hace del mundo su mundo. Una artista artista hace de su mundo el mundo. Por un momento. Por el tiempo que toma observar o escuchar o ver o leer la obra de arte. Como un cristal de cuarzo, la obra de arte parece contener el todo y sugerir eternidad. Y sin embargo es solo el bosquejo cartográfico de un explorador. Un mapa de litorales en una costa brumosa. (Le Guin, 2021, p. 206)

El diseño de proyectos transmedia puede recurrir a esta lógica de intervenir nuestro espacio-tiempo y convertirlo en algo distinto. El "hacer el mundo nuestro mundo" es un acto de apropiación radical que nos permite reimaginar los horizontes de posibilidad. Es, podríamos decir, un acto de montaje, de reorganización de las posibilidades desplegadas en un tiempo histórico determinado. Por ello, dentro de las tres dimensiones operativas del modelo que aquí describo, el montaje reina sobre los procesos de investigación y escritura en tanto dinámica de ordenamiento de la expresión.

El montaje puede entenderse como la arquitectura de la mirada (de la sensibilidad y la inteligencia) a partir de los medios que tenemos al alcance. Es la transformación de esos elementos de la realidad de los que habla Ursula K. Le Guin en una nueva lógica de sentido. El montaje nos permite, por lo tanto, renovar las relaciones que sostienen a la realidad. No hay que olvidar que el montaje, como nos sugiere Alexander Kluge, tiene que ver con lo que no está presente, con lo oculto, 
con las omisiones:

La omisión, lo oculto, el recorte, la confrontación de dos improbabilidades que juntas resultan en un pedazo de vida, la negativa a inmovilizar lo vital con los recursos de la denominación directa, el total aprovechamiento de la denominación indirecta: todo eso pertenece al mundo formal del montaje, ya sea en el cine, la música o en un libro. (Kluge, 2014, p.40)

El montaje puede ser pues una práctica de descubrimiento, un trabajo de revelar imágenes latentes que subyacen a las configuraciones vigentes de nuestro mundo en crisis.

En los últimos años, a partir de un hallazgo en la Poética del cine de Raúl Ruiz (2000), he trabajado el diseño de proyectos a partir de una dicotomía que Ruiz aplica al estudio de la memoria: la memoria como ministerio (aquellas estructuras oficiales que reinan sobre el relato histórico) y la memoria como misterio (las posibilidades de introducir lo desconocido y el descubrimiento como tensiones que dan sentido al relato histórico). Lo oculto, el recorte, la denominación indirecta de las que habla Kluge son dispositivos de misterio, dispositivos que introducen fisuras en las configuraciones de sentido ministeriales, en los dispositivos de control y opresión que operan en el mundo contemporáneo. El montaje y, por consiguiente, la investigación y la escritura, como prácticas que le dan sentido al desarrollo de proyectos transmedia, son pues prácticas con implicaciones políticas y éticas.

El montaje es un campo de acción expandido no solamente porque nos permite diseñar estrategias de integración entre distintos códigos expresivos y soportes mediáticos, sobre todo cuando hablamos de proyectos transmedia; lo es también porque, al vislumbrar otras configuraciones de mundo, expande los esquemas de significación de la experiencia compartida y nos da herramientas para reimaginar los horizontes de lo posible. Es un dispositivo de intervención del ministerio desde el cual tejer resistencias, aunque sean poéticas, a los sistemas de destrucción que atraviesan fronteras. Durante más de una década, mediante esta búsqueda desplegada en distintas escalas, he intentado articular configuraciones de mundo alternativas, fisuras en las murallas del ministerio de la memoria desde las cuales mirar otras formas de ser y estar juntos. El montaje nos brinda las herramientas para tejer mapas de realidad desde donde habitar otra realidad. Hay que dar muerte a lo real para que otro mundo aparezca en el horizonte. Y hay que hacerlo continuamente. Latinoamérica es una región fracturada, pero su herencia es rica en diversidad. Esta diversidad puede inspirar caminos que nos conduzcan a direcciones de restauración de las posibilidades de vida en este mundo agonizante. Como artistas, tenemos el poder de revelar configuraciones de sentido alternativas y, en consecuencia, hacer visibles sus modos de habitación.

\section{Notas al final}

1. En un libro reciente, he desarrollado la idea de sitio de imaginación y sitio de enunciación como pilares de toda práctica creativa en el marco de lo que denomino crítica práctica de la comunicación (ver Martínez Zárate, 2021), en este caso, aprovecho la temática que enmarca este número de Hipertext para comenzar con algunas reflexiones y cuestionamientos sobre el papel del arte documental en la Latinoamérica de la tercera década del siglo XXI.

2. El título "¡Muerte a lo real!" surge en primavera de 2021 en el un taller lanzado desde mi estudio, un taller que buscó entretejer la práctica documental con el pensamiento crítico; algunos de los contenidos pueden consultarse aquí: http://pedagogia.pablomz. info/muerte-a-lo-real/

3. Se llevaron a cabo varios talleres de realización de webdocumentales con este código, trabajando principalmente con celulares en contextos rurales de los estados mexicanos de Oaxaca y Estado de México.

4. El acervo abarca de 1965 a 2005 y comprende cientos de miles de documentos fotográficos. La Universidad Iberoamericana, a través de la Biblioteca Francisco Xavier Clavigero, resguarda estas imágenes y las abre a todos los usuarios de la comunidad universitaria. Entre las fotografías, se ubican los fondos del movimiento estudiantil con la finalidad de su publicación en un libro en 2018. Realizaron el trabajo de catalogación y digitalización de todas las fotografías, una labor sin la cual la realización de ambas piezas hubiera sido imposible.

5. La noción del archivo como acontecimiento la he desarrollado en distintos textos y documentos, incluyendo un librito que lleva el mismo nombre que, además de contener el guion de la película $\mathrm{El}$ monopolio de la memoria,

6. Soy de la creencia que esta figura del investigador-artista, así como de la investigación artística o la investigación-creación como vehículo de producción de conocimiento sobre la realidad, se deben impulsar cada vez más en México y Latinoamérica. Dicha convicción responde a la necesidad doble de, primero, ampliar los caminos de realización de carreras creativas, y segundo, introducir nuevas modalidades de exploración de los fenómenos de la realidad que confirmen el valor del arte como fuente de intuiciones e ideas sobre los fenómenos del mundo y nuestra acción dentro de él.

7. https://vimeo.com/470175237

8. La memoria se puede consultar en: https://pablomz.info/memoria-interactiva/

9. Traducción del autor del inglés: "An archeology of the archive, methodologically speaking, consists in the adoption of a set of strategies that allow us to look at the archive as a multiplicity of puncta, or details, that should be treated as indexes marking spatial and temporal relationships between the past and the present, which, in the context of a digital economy, are also shaped by the media that form them. Survey, record, and stratigraphy are among the other tools that facilitate orientation within the cumuli of materials that form the archive, the puncta, both spatial and temporally" (Giannachi, 2016, p. 35).

\section{Bibliografía}

Álvarez, S. (1988). Arte y compromiso. Hojas de cine, testimonios y documentos del nuevo cine latinoamericano, 3, 35-37.

Freire, P. (1970). Pedagogía del oprimido. Siglo XXI.

Giannachi, G. (2016). Archive Everything. Mapping the Everyday. MIT Press.

Haraway, D. (1991). Simians, Cyborgs, and Women: The Reinvention of Nature. Routledge.

Le Guin, U. (2021). Hacer Mundos. En Gerber-Bicecci, V. (ed.), En una orilla brumosa. Cinco rutas para repensar los futuros de las artes 
visuales y la literatura, (pp. 205-210). Gris tormenta.

Kluge, A. (2014). 120 historias del cine. Caja Negra.

Martínez-Zárate, P. (2018). Hacia una crítica práctica de la comunicación: ideas desde el arte mediático, la arqueología de los medios y la filosofía de máquinas. Revista Iberoamericana de Comunicación, (36), 199-241. https://ric.ibero.mx/index.php/ric/article/view/32/26

Martínez-Zárate, P. (2021). Máquinas para ver y oír al límite del tiempo: hacia una crítica práctica de la comunicación (Tesis doctoral, Universidad Iberoamericana). http://ri.ibero.mx/handle/ibero/2368

Rocha, G. (2004). La estética del hambre [texto original de 1965]. Ramona, revista de artes visuales, (41), 52-55. http://70.32.114.117/ gsdl/collect/revista/revistas/ramona41.pdf

Ruiz, R.(2000). Poética del Cine. Editorial Sudamericana.

Trujillo, 0.(2012). Aforismos contenidos en Bitácora Ciudad Merced. Narrativa a la deriva.

\section{CV}

Pablo Martínez-Zárate. Artista, documentalista e investigador mexicano cuyo trabajo explora los cruces entre memoria, cuerpo y territorio desde la práctica experimental y documental en medios múltiples. Es reconocido en México y Latinoamérica como pionero y uno de los principales exponentes de la narrativa documental web e inmersiva. Ha expuesto individualmente en recintos importantes de México y su trabajo se ha incluido en festivales como DocsMX y Ambulante en México, MIDBO en Bogotá, o IDFA en los Países Bajos. Su último libro se titula "Los poderes de la imagen. Ensayo sobre cuerpo y muerte en la cultura audiovisual". Cuenta con una maestría en arte digital por la Universidad de Edimburgo y un doctorado en comunicación por la Universidad Iberoamericana, donde es académico de tiempo completo y fundador del Laboratorio Iberoamericano de Documental. Ha sido profesor invitado en la EICTV San Antonio de los Baños, Emerson College Boston, University of Southern California y Zurich University of the Arts. https://pablomz.info

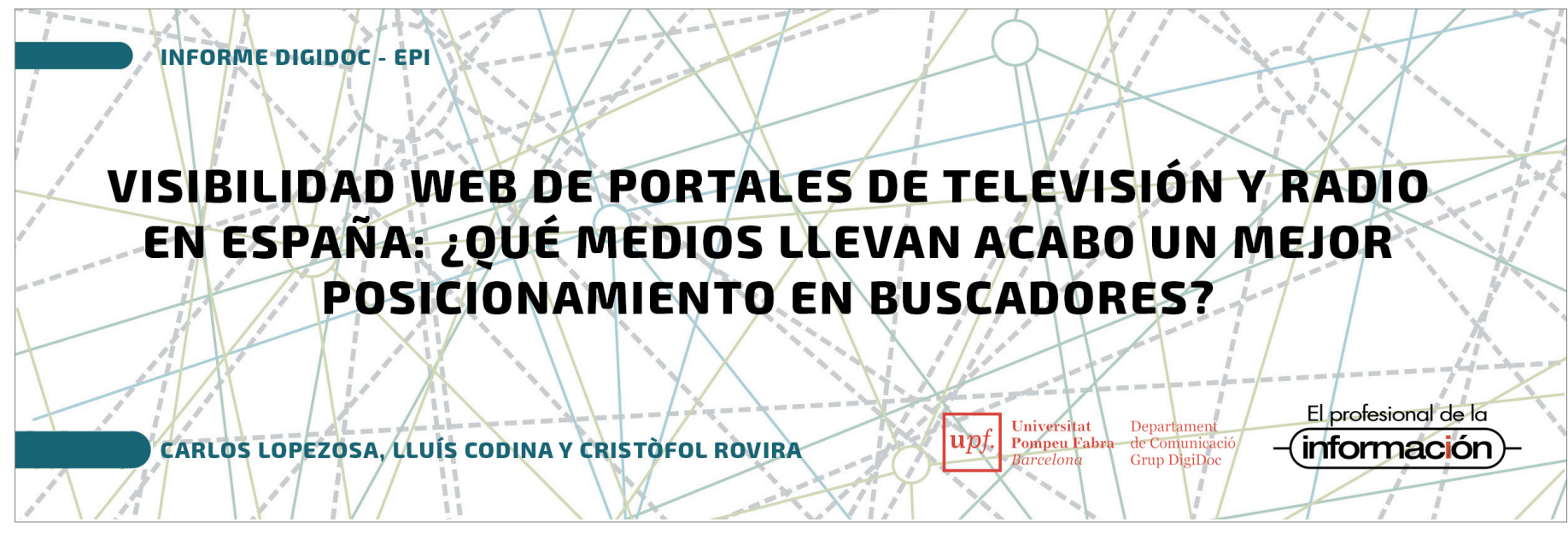

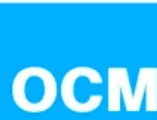

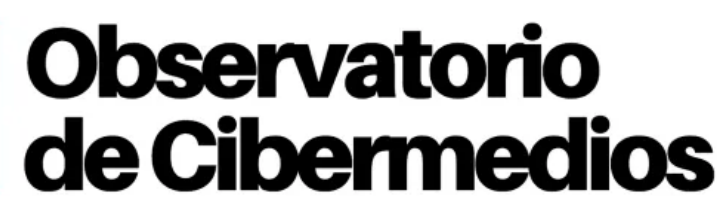

https://observatoriocibermedios.upf.edu/

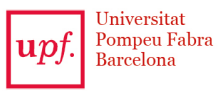

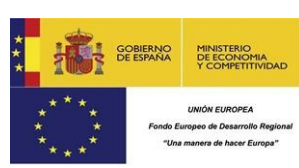

El Observatorio de Cibermedios es una producción del Grupo de Investigación en Documentación Digital y Comunicación Interactiva (DigiDoc) del Departamento de Comunicación de la Universitat Pompeu Fabra.

El Observatorio de Cibermedios (OCM) forma parte del proyecto del Plan Nacional "Narración interactiva y visibilidad digital en el documental interactivo y el periodismo estructurado". RTI2018-095714-B-C21 (MINECO/FEDER), Ministerio de Ciencia, Innovación y Universidades (España). 